\title{
Partial prestressing as a method of equal- strength structures bending approaching
}

\author{
Valery Khuranov*, Aslan Kaziev, Akhmed Shogenov, and Azamat Balov \\ Kabardino-Balkarian State University, 360004, Nalchik, Russia
}

\begin{abstract}
The use of partial prestressing as a way to save materials in building structures is observed in the article. The redesign of a typical prestressed reinforced concrete rafter beam with a span of $12 \mathrm{~m}$ with parallel belts, in which partial prestressing was applied, made it possible to reduce the main working high-tensile reinforcement consumption by more than $30 \%$ and increase the high-tensile reinforcement using efficiency from 0.58 to 0.74 .
\end{abstract}

\section{Introduction}

The most rational type of structure are the elements of equal resistance, in all sections of which the ratio of the moment from external loads to the moment from internal forces is constant - they do not have excessive safety margins. Such elements are the most costeffective and economical in terms of material consumption.

The design of reinforced concrete structures of equal strength, especially if they use prestressed high-tensile reinforcement, is a complex process. Nevertheless, it is possible to come closer to such a solution, it is reasonable to strive for this, and one of the main methods is the development of reinforced concrete structures with partial prestressing along the length of the element $[1-3]$.

To meet the requirements for crack resistance of reinforced concrete structures reinforced with high-tensile steel, in many cases it is possible to pre-stretch not all longitudinal reinforcement, but only part of it. Such reinforcement is usually called mixed or partial prestressing. It allows unstressed reinforcement to be cut off in the span in accordance with the materials diagram, which makes it possible to reduce the reinforcement consumption and bring the structure closer to an element of equal resistance with the minimum required material costs [4 - 5].

In structures with partial prestressing, due to a decrease in the compression force, losses from concrete creep are reduced. It becomes possible to reduce the concrete class and transfer strength.

A fundamental feature of reinforced concrete structures with partial prestressing is that in them part of the longitudinal reinforcement is not subjected to tension. This makes it possible to provide for breaks of non-stressed reinforcement in the span in accordance with the diagrams of internal forces, which ultimately aims to reduce the consumption of steel.

These structures, in contrast to conventional prestressed ones, have greater flexibility and energy absorption capacity, which is especially important for construction in seismic

\footnotetext{
* Corresponding author: Valeriy-archi@mail.ru
} 
regions. In them, due to a decrease in the compression force, losses from short-term and long-term concrete creep are significantly reduced [6 - 7]. It becomes possible to reduce the concrete class and transfer strength, to facilitate reinforcement work. This leads to a decrease in the labor intensity of manufacturing and the technological energy consumption of structures.

\section{Determination of the partial prestressing factor}

Partial prestress coefficient is the ratio of the maximum allowable force in the prestressed reinforcement to the sum of the maximum allowable forces in the prestressed and nonstressed reinforcement of the tensioned section zone, i.e.,

$$
K_{p}=\frac{R_{s p} A_{s p}}{R_{s p} A_{s p}+R_{s} A_{s}}
$$

where,

$R_{s p}, A s_{p}$ and $R_{s}, A_{s}$ are the design resistances and cross-sectional areas of prestressed and untensioned reinforcement;

Fig. 1 presents a diagram of the deformation of reinforcing steel of class A-1000, built according to the calculated values of the characteristics $\sigma_{0,2}=R s ; \sigma_{u}=\eta R \mathrm{~s} ; \sigma_{e l}=\beta R_{S}$ and others. Up to the conditional elastic limit $\sigma e l$, corresponding to a deformation of 0.002 , a linear Hooke dependence is adopted, and at higher stresses, the deformation curve of steel is described by the dependence adopted in the International Standards International Federation for Structural Concrete:

$$
\begin{gathered}
\sigma_{S}=\sigma_{e l}+\left(\sigma_{u}-\sigma_{e l}\right) \frac{K_{S}\left(\frac{\varepsilon_{S}-\varepsilon_{e l}}{\varepsilon_{u}-\varepsilon_{e l}}\right)-\left(\frac{\varepsilon_{S}-\varepsilon_{e l}}{\varepsilon_{u}-\varepsilon_{e l}}\right)^{2}}{1+\left(K_{S}-2\right) \frac{\varepsilon_{S}-\varepsilon_{e l}}{\varepsilon_{u}-\varepsilon_{e l}}} \\
K_{S}=\frac{E_{S}\left(\varepsilon_{u}-\varepsilon_{e l}\right)}{\sigma_{u}-\sigma_{e l}}
\end{gathered}
$$

$\sigma_{e l}$ and $\varepsilon_{e l}$ denote the conditional elastic limit and corresponding deformation;

$\sigma_{u}$ and $\varepsilon_{u}$ denote temporary resistance and corresponding deformation.

When prestressing the reinforcement to stresses above the conditional yield strength $\sigma_{s p}>\sigma_{0.2}$ prestress losses occur due to stress relaxation $\sigma_{l}$ without deformation change (vertical segment in Fig. 1) and other losses with deformation change. The sum of all losses is $\sigma_{l o s}$, and the steady-state prestress $-\sigma_{s p 2}$.

As a result of the prestressing effect and the removal of some of the plastic deformations, the conditional elastic limits increase from $\sigma_{e l}$ up to $\sigma_{e l}^{\prime}$ and fluidity with $\sigma_{0,2}$ up to $\sigma_{0,2}^{\prime}$. 


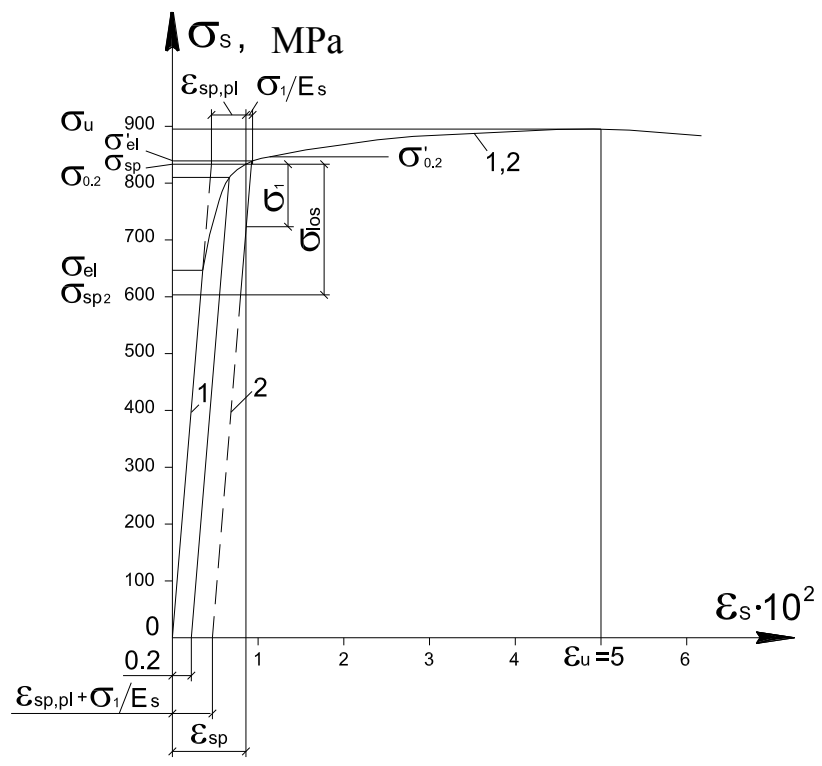

Fig. 1. Deformation diagrams of reinforcing steel of class A-1000: 1 - initial, 2 - at prestressing above the elastic limit

In contrast to the equation (2), which describes the initial deformation diagram of hightensile steel, after prestressing it will take the form:

$$
\begin{gathered}
\sigma_{S}=\sigma_{e l}^{\prime}+\left(\sigma_{u}-\sigma_{e l}^{\prime}\right) K_{S}^{\prime} \frac{\left(\frac{\varepsilon_{S}-\varepsilon_{e l}^{\prime}}{\varepsilon_{u}-\varepsilon_{e l}^{\prime}}\right)-\left(\frac{\varepsilon_{S}-\varepsilon_{e l}^{\prime}}{\varepsilon_{u}-\varepsilon_{e l}^{\prime}}\right)^{2}}{1+\left(K_{S}-2\right) \frac{\varepsilon_{S}-\varepsilon_{e l}^{\prime}}{\varepsilon_{u}-\varepsilon_{e l}^{\prime}}} \\
K_{S}^{\prime}=\frac{E_{S}\left(\varepsilon_{u}-\varepsilon_{e l}^{\prime}\right)}{\sigma_{u}-\sigma_{e l}^{\prime}}
\end{gathered}
$$

$E_{S}$ and $\varepsilon^{\prime}{ }_{e l}=\sigma_{e l}^{\prime} / E_{s p}$ are measured from the new origin.

When $\varepsilon_{s}$ or addiction $-\varepsilon_{s}$ linear.

The deformed deformation under prestressing will be $\varepsilon_{s p, p l}+\sigma_{1} / E_{s}$, where $\varepsilon_{s p, p l}$ is the stress plastic deformation $\sigma_{s p}>\sigma_{e i}$, and $\sigma_{l} / E_{s}$ - the same, at loss of prestress from relaxation of stress $\sigma_{l}$.

The experimental data show that the following relationship between $\varepsilon_{s p, p l}$ and $\sigma_{s p}$ show:

$$
\varepsilon_{s p, p_{l}}=0.25\left(\frac{\sigma_{s p}}{R_{s p}} 0,8\right)^{3}
$$

Fig. 1 shows that even at a very high prestress, the conventional yield strength for the reinforcement under consideration increases insignificantly. So, for $\sigma_{s p}=840 \mathrm{MPa}$ conventional yield strength increases with $\sigma_{0.2}=815 \mathrm{MPa}$ to $\sigma_{0.2}=845 \mathrm{MPa}$, that is, less than $5 \%$. 
In this regard, when determining the coefficient of mixed reinforcement (partial prestressing) for the elements in which prestressed and non-stressed reinforcement are adopted of the same class, it is possible to take $\sigma_{0,2} \approx \sigma_{0.2}^{\prime}$ :

$$
K_{P}=\sigma_{0.2}^{\prime} A_{s p} /\left(\sigma_{0.2}^{\prime} A_{s p}+\sigma_{0.2} A_{s}\right)=A_{s p} /\left(A_{s p}+A_{s}\right)
$$

\section{Ultimate stresses in reinforced concrete bending structures reinforcement with partial prestressing}

To ensure the effective use of structures with partial prestressing, it is necessary to achieve the conditions under which the stresses in prestressed and non-prestressed reinforcement in the limiting state reach the design resistances.

In the structures of which high-tensile stress-free reinforcement $S$ and pre-stressed $S_{p}$ taken of the same class, with an increase in the load, the development of plastic deformations in the reinforcement $S_{p}$ starts earlier than in the reinforcement $S$, therefore, in the latter, stresses grow faster [8 - 10]. Under certain conditions, at the moment of the beam destruction, the stresses in the untensioned reinforcement $S$ equal to the stresses in the reinforcement $S_{p}$ and at the moment of destruction of the beam, they become equal to the design resistance of the reinforcement. Which contributes to the strength of the reinforcement most efficient use. This can be achieved with appropriate values $\xi / \xi_{R}$ and prevoltage level $\sigma_{s p 2} / \sigma_{0,2}$.

Earlier, on the basis of experimental studies [11], the dependences of the class A-1000 high-tensile untensioned reinforcement use degree in the elements of heavy concrete at different levels of prestressing of reinforcement of the same class were determined. $\quad \xi / \xi_{R}$ is equal to $0.42 ; 0.5$ and 0.58 at $\sigma_{s p 2} / \sigma_{0.2}$ is equal respectively to 0,$56 ; 0,7$ and 0,84 . When $\xi / \xi_{R}$ $=0.62 \ldots 0.78$, that is, at rather high values of the compressed zone height, the stresses in non-stressed high-tensile reinforcement are below the limit by no more than $10 \%$. This indicates that the elements with mixed reinforcement can be effective with a wide range of variation in the height of the compressed section zone (or percentage of reinforcement - $\mu$ ) and the partial pre-stress level.

\section{Partially prestressed reinforced concrete beam}

For a quantitative assessment of the partial prestressing effectiveness, we redesign a typical reinforced concrete rafter beam with a span of $12 \mathrm{~m}$ with parallel chords $1 \mathrm{BSP} 12-4 \mathrm{~A}-1000$ series $1.462 .1-1 / 88$

Let us take the unchanged dimensions of the beam (Fig. 2), the load $q=6.5 \bullet 6=39 \mathrm{kN} / \mathrm{m}$ and the characteristics of materials. Based on the section strength in the middle of the span at $K_{P}=0.6$ and $A_{s p}+A_{s}=10.05 \mathrm{~cm}^{2} ; A_{s p}=6 \mathrm{~cm}^{2}$ (3Ø16 A-1000), $A_{s}=4 \mathrm{~cm}^{2}$ (2Ø16 A-1000), it follows that the moment of internal forces is $685 \mathrm{kN} \cdot \mathrm{m}$, what is more torque from the external load $(668 \mathrm{kN} \bullet \mathrm{m})$.

In case of breakage of class A-1000 two untensioned reinforcement bars, the moment taken by the section will be $445 \mathrm{kN} \cdot \mathrm{m}$. Equating it to the moment from external forces, we find the distance $(250 \mathrm{~cm})$ from the left support to the place of the theoretical break of the indicated rods. By the value of the shear force in this section, we find the length of the start of the cut off reinforcement for the theoretical break place of $52 \mathrm{~cm}$. 


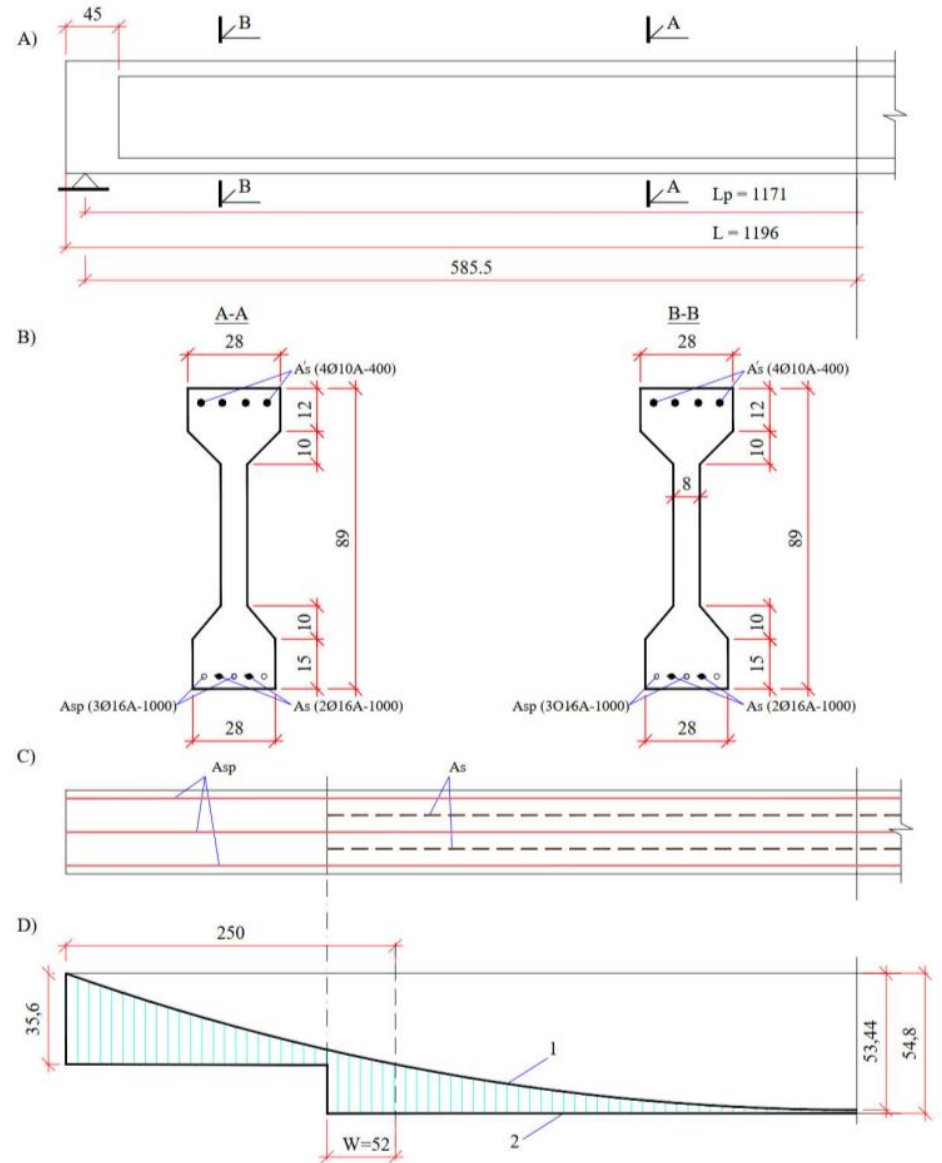

Fig. 2. The proposed prestressed reinforced concrete beam: $A$ - general view; $B$ - sections; $C$ - bottom reinforcement plan; $D$ - diagrams of moments from external load (1) and internal forces (2)

With the adopted reinforcement, the bearing capacity in all sections is ensured. The safety factor (shaded area in Fig. 2) is the smallest possible. Reinforcement efficiency factor $\eta=0,74$, which is 1.3 times higher than in a typical solution (Table 1). The consumption of the main working armature is significantly reduced (by $30 \%$ ), which is a consequence of the reinforcement breakage possibility at partial prestressing.

Table 1. Consumption of class A-1000 working reinforcement in a reinforced concrete beam with a span of $12 \mathrm{~m}$ under load $\mathrm{q}=39 \mathrm{kN} \cdot \mathrm{m}$

\begin{tabular}{|c|c|c|c|c|c|}
\hline \multirow[t]{2}{*}{ Beam type } & \multicolumn{2}{|c|}{ Working reinforcement $S$} & \multicolumn{2}{|c|}{$\begin{array}{c}\text { Working } \\
\text { reinforcement } \\
\text { consumption }\end{array}$} & \multirow[t]{2}{*}{$\begin{array}{c}\text { Reinforcement } \\
\text { efficiency factor } \\
\eta\end{array}$} \\
\hline & prestressed & untensioned & $\mathrm{kg}$ & $\%$ & \\
\hline Typical & $4 \varnothing 20 \mathrm{~A}-1000$ & 0 & 118.4 & 100 & 0.58 \\
\hline Proposed & $3 \varnothing 16$ A-1000 & 2016 A-1000 & 82.1 & 69.3 & 0.74 \\
\hline
\end{tabular}




\section{Conclusions}

Redesign of a typical prestressed reinforced concrete rafter beam with a span of $12 \mathrm{~m}$ with parallel belts, in which mixed reinforcement was applied, made it possible to reduce the main working high-tensile reinforcement consumption by more than $30 \%$ and increase the reinforcement use efficiency from 0.58 to 0.74 .

\section{References}

1. D.R. Mailyan, R.L. Mailyan, V.Kh. Khuranov, Methods for the manufacture of reinforced concrete structures with variable prestress along the length of the element, News of higher Educational Institutions. Construction 5 (2004).

2. D.R. Mayilyan, V.Kh. Khuranov, Design of reinforced concrete structures of equal resistance (Print Center, Nalchik, 2015).

3. V.Kh. Khuranov, A.A. Khuranov, Engineering Journal of Don 4 (2017). Information on ivdon.ru/ru/magazine/archive/n4y2017/4022.

4. M.S. Stemkovsky, Z.A. Meretukov, V.D. Mailyan, A.Yu. Kubasov, Engineering Journal of Don, (2017). Information no ivdon.ru/ru/magazine/archive/n4y2017/4420.

5. N.G. Golovin, I.A. Trifonov, V.F. Saprykin, Improvement of methods of calculation and design of building structures and methods of their construction (1985) 62 - 67 .

6. I.I. Gradyuk, M.I. Stasyuk, Concrete and reinforced concrete 3 (1983).

7. G.I. Berdichevsky, Yu.P. Gushcha, V.G. Kramar, Proceedings of the Philosophical Institute symposium on partial prestressing, Bucharest 1, 195-204 (1980).

8. B.V. Karabanov, O.F. Ilyin, Concrete and reinforced concrete 3, 23-25 (1988).

9. Yu.V. Krasnoshchekov, Concrete and reinforced concrete 12, 20-21 (1985).

10. S.A. Madatyan, Concrete and reinforced concrete 1, 2-5 (1997).

11. D.R. Mailyan, R.L. Mailyan, V.K. Osipov, Concrete and reinforced concrete 2, 18-20 (2002). 